\title{
A TEORIA DA SOLUÇÃO INVENTIVA DE PROBLEMAS (TRIZ) NA IDENTIFICAÇÃO DE OPORTUNIDADES DE PRODUÇÃO MAIS LIMPA
}

\section{THE THEORY OF INVENTIVE PROBLEM SOLVING (TRIZ) IN THE IDENTIFICATION OF CLEANER PRODUCTION OPPORTUNITIES}

\author{
Flávio Issao Kubota ${ }^{1}$; Leandro Cantorski da Rosa ${ }^{2}$ \\ ${ }^{1}$ Universidade Federal de Santa Maria - UFSM - Santa Maria - Brasil \\ flavioissao.kubota@gmail.com \\ ${ }^{2}$ Universidade Federal de Santa Maria - UFSM - Santa Maria - Brasil \\ leski78@hotmail.com
}

\begin{abstract}
Resumo
Inovação e melhores resultados na produção têm sido requisitos essenciais na indústria de alimentos. Paralelamente, ideias simples e criativas contribuem para o desenvolvimento das empresas. Desse modo, esta pesquisa tem como objetivo investigar oportunidades de aplicação da produção mais limpa (PML) por meio da metodologia da Teoria da Solução Inventiva de Problemas (TRIZ), visando identificar pontos críticos na produção de indústrias de laticínios de pequeno porte. Para execução do estudo, realizou-se pesquisa de caráter qualitativo e natureza exploratória, sendo executado um estudo de caso em duas usinas de laticínios de pequeno porte do Rio Grande do Sul (RS). Os resultados apontam diversas oportunidades de PML nos casos estudados, principalmente em relação às perdas de água e soro de leite no processo produtivo. Ao final da pesquisa, concluiu-se que os conceitos da TRIZ foram importantes na organização do processo criativo, na definição esclarecedora dos problemas encontrados e, por fim, na busca por soluções inventivas.
\end{abstract}

Palavras-chave: produção mais limpa; TRIZ; indústria de laticínios; melhoria de processos.

\section{Introdução}

A indústria alimentícia tem buscado, constantemente, a inovação e os melhores resultados nos processos e produtos, considerando-se a alta competitividade, concorrência no ramo e clientes cada vez mais exigentes. Ainda, os esforços pelas melhores práticas ambientais é outro aspecto que vem sendo requisitado pelas partes interessadas ao negócio das organizações, uma vez que grande quantia dos recursos utilizados nos processos não são renováveis (KUBOTA et al, 2010). Para Mendes (2009), o crescente interesse em preservar o meio ambiente proporciona um movimento de conscientização da população, no sentido de se consumir produtos e serviços que gerem menor impacto ambiental, exigindo adequações por parte das organizações.

Desse modo, Righetti et al (2005) ressalta que a inquietação relativa aos assuntos ambientais 
se inseriu na rotina das empresas, e essas podem utilizar diferentes estratégias para a gestão ambiental, que pode variar de uma postura reativa até uma atitude estratégica, de forma que a variável ambiental seja compreendida como uma oportunidade de se obter vantagem competitiva, ao invés de um ônus. No entanto, evidencia-se maior quantidade de estratégias reativas, apesar da importância crescente do tema nos últimos anos (RIGHETTI et al, 2005).

A indústria de laticínios tem importância significativa a nível mundial, nacional e gaúcho, na economia. Dados da Food and Agriculture Organization of the United Nations (FAO, 2008) apontam o Brasil como sexto colocado em produção de leite de vaca no mundo, produzindo 27.752 milhões de toneladas (4,8\% da produção mundial). Em território nacional, o Rio Grande do Sul aparece em segundo lugar, com 2.944 milhões de litros anuais (EMBRAPA, 2007). Além disso, acredita-se que a produção mais limpa (PML) pode gerar benefícios importantes ao ramo de laticínios, pois segundo Nguyen e Durham (2004) essa indústria possui fonte significativa de contaminantes, e ainda assim existe um número limitado de estudos na literatura em PML para empresas de laticínios e derivados.

Ideias criativas são possíveis fontes de inovação (CARVALHO; FERREIRA, 2005). A Teoria da Solução Inventiva de Problemas (TRIZ) tem a proposta de organizar o processo criativo. Em síntese, trata-se de uma metodologia que busca a excelência em projeto e inovação. Além disso, aplicações da TRIZ para os problemas relacionados a design de produtos para sustentabilidade cooperativa e eco-eficiência são documentadas na literatura, entretanto são raros (HOCKERTS, 1999; JONES; MANN, 2001; CHEN; LIU, 2001; KOBAYASHI, 2006). E o uso explícito desse método dentro da PML não está documentado até hoje, de acordo com o conhecimento dos autores (FRESNER et al, 2010).

Assim, com o intuito de alinhar a importância da referida indústria à necessidade de utilização mais racional de recursos, este trabalho tem como objetivo investigar oportunidades de aplicação da produção mais limpa (PML) em processos produtivos através de conceitos da metodologia TRIZ, visando identificar os pontos críticos da produção e ressaltar a importância ambiental em reduzir e/ou reaproveitar o consumo de recursos naturais.

\section{TRIZ - conceitos fundamentais}

A TRIZ pode ser definida como uma metodologia heurística, baseada em conhecimento e direcionada ao ser humano, objetivando a solução de problemas inventivos (CARVALHO, 2007). De forma resumida, a TRIZ é utilizada da seguinte maneira: define-se o problema específico a ser solucionado, para que depois seja elaborado o problema genérico. Em seguida, parte-se para a solução genérica do problema em questão, e posterior elaboração da solução específica (CARVALHO, 2007). A Figura 1 ilustra a estrutura de aplicação da metodologia. 
Figura 1 - Estratégia de resolução de problemas da TRIZ

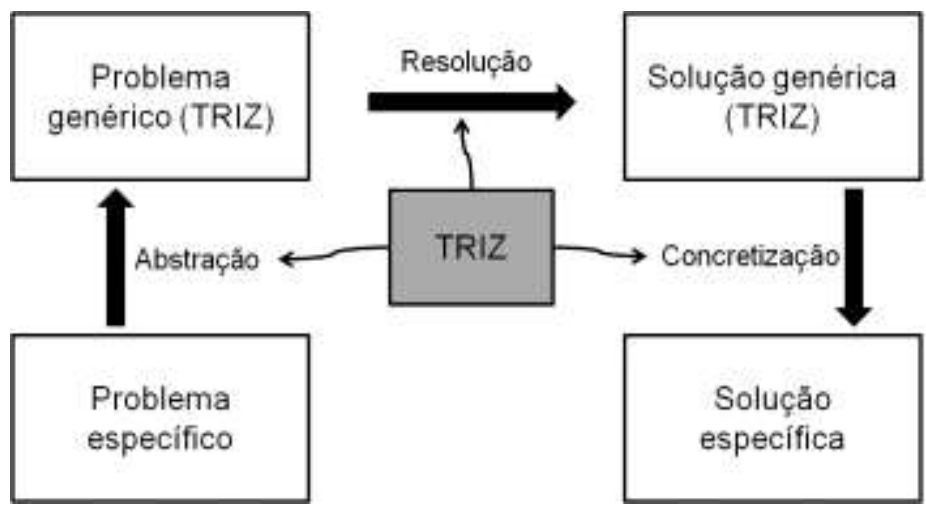

Fonte: Carvalho (2007)

Para o entendimento da metodologia e estratégia de aplicação, é importante a compreensão de três conceitos fundamentais da TRIZ: idealidade, recursos e contradições. Neste trabalho, serão utilizados apenas os dois primeiros conceitos.

Idealidade é a razão entre o número de funções desejadas e o número de funções indesejadas do sistema (CARVALHO; BACK, 2001; CARVALHO; HATAKEYAMA, 2003; FRESNER et al, 2010). Ainda, a equação da idealidade visa o direcionamento ao sucesso, com maiores benefícios e menores custos e danos (JANTSCHGI; MANN, 2005). De acordo com Yang e Chen (2011), o sistema ideal (utópico) executa apenas funções desejadas, utilizando todos os recursos possíveis. Por fim, a metodologia TRIZ interpreta a idealidade como o ponto de partida para a resolução do problema em questão, evitando, ao máximo, o processo de tentativa e erro para buscar soluções.

No entanto, definir o que é desejável e indesejável pode variar conforme a perspectiva do analista ou das condições do problema analisado. Malkin e Malkin (2003) sintetizam isso, afirmando que a idealidade varia de acordo com cada situação. Dessa forma, define-se o Resultado Final Ideal (RFI), que equivale à idealidade local e ajuda, de maneira clara, a definir os limites do problema, inibindo soluções não ideais, evitando soluções de compromisso e instigando a criação de conceitos inovadores, bem como expressa o resultado esperado para o problema em estudo (DEMARQUE, 2005).

Exemplos da utilização desse conceito na PML podem ser encontrados na literatura. Li et al (2001) aplicaram o conceito de idealidade ao propor a substituição de dois equipamentos no setor de destilação em uma indústria. Por meio dos conceitos, obtiveram-se projeções de redução no consumo de vapor em $23,7 \%$ e $27,7 \%$, respectivamente. Fresner et al (2010) utilizou a TRIZ na melhoria do subprocesso de decapagem de uma organização do setor químico. Através da análise funcional - outra ferramenta utilizada na TRIZ - os autores puderam elaborar o resultado final ideal (RFI), ou seja, a idealidade local no subprocesso, que foi uma superfície livre de contaminantes para a etapa seguinte do processo. 
Os recursos são elementos do sistema que ainda não foram aplicados na execução de funções desejadas no sistema (CARVALHO; BACK, 2001; CARVALHO; FERREIRA, 2005; CARVALHO, 2007). Existem diversos exemplos de aplicação desse conceito, visando sempre imitar a Natureza, principal referência quanto ao aproveitamento dos recursos naturais (CARVALHO; FERREIRA, 2005). Durante a pesquisa, não se encontrou evidências da utilização desse conceito na indústria de laticínios, mais especificamente. No entanto, há referências na indústria de alimentos que podem ser enquadrados nessa situação. Freitas e Ribas (2008), Coutinho, Rodrigues e Silva (2009) e Silva et al (2009) são exemplos disso.

\section{A PML na indústria de laticínios}

$\mathrm{Na}$ indústria de laticínios, assim como no ramo alimentício, há, de forma geral, problemas relacionados ao tratamento de desperdícios durante o processo produtivo, tanto de recursos energéticos (água, luz, vapor, etc.) como de processos, produtos e subprodutos - avarias, condenações, contaminações, etc. (KUBOTA et al, 2010).

Resumidamente, a PML tem por objetivo a otimização no uso de materiais e energia por meio da modificação no processo (substituição de matéria-prima, mudanças de tecnologia, mudanças operacionais nas práticas), reciclagem interna e externa (FRESNER et al, 2010). Os mesmos autores afirmam que essas estratégias agem como princípios gerais e, posteriormente, são tratados os efluentes, resíduos e emissões que acarretam em maiores prejuízos financeiros. Thrane et al (2009) complementam, afirmando que a PML se trata de uma estratégia preventiva que pode abordar processos de fabricação e produtos, e entende o desenvolvimento de produtos mais limpos como o tipo de melhoria mais extrema.

Segundo a UNEP (2002) e Medeiros et al (2007), há seis tipos de soluções distintas na estrutura da metodologia de PML: housekeeping (boas práticas), reutilização e reciclagem, substituição de materiais e químicos perigosos, otimização de processos, mudança tecnológica, e inovações e desenvolvimento de produtos mais limpos (ecodesign). Nesta pesquisa, será abordada, essencialmente, as modificações nos processos, através de boas práticas e reutilização de recursos.

Exemplos podem ser vistos em Özbay e Demirer (2007), Schneider (2008), Brum et al (2009) e Kubota et al (2010), onde foram desenvolvidas pesquisas visando à identificação de oportunidades PML no processamento de produtos lácteos. Como resultados, foram levantadas alternativas e possibilidades de redução no consumo de água e reaproveitamento da mesma, bem como oportunidades de minimização em resíduos e emissões. Em outra abordagem, Silva (2006) realizou um diagnóstico ambiental acerca do consumo de água e geração de resíduos em micro e pequenas empresas de laticínios, desenvolvendo um sistema multimídia direcionado para explicar 
as vantagens competitivas de se realizar um controle preventivo da geração de efluentes, resíduos e emissões.

Berlin et al (2007) entendem que o aumento na venda de produtos lácteos afeta o impacto ambiental, em uma perspectiva do ciclo de vida dos mesmos, uma vez que isso gera mais resíduos de leite, uso de agentes de limpeza e água. Assim, os autores projetaram um método heurístico para calcular o sequenciamento da produção e verificar se essa alcançaria a melhor alternativa, e conseguiram resultados relevantes integrando o referido método à metodologia convencional de ciclo de vida.

Na Austrália, Fisher e Scott (2008) realizaram uma avaliação no campo farmacêutico e em uma fazenda de laticínios, com o intuito de prevenir possíveis ameaças na região através de gerenciamento preventivo na emissão de produtos farmacêuticos, evitando a contaminação microbiológica.

\section{Metodologia da pesquisa}

Esta pesquisa tem abordagem qualitativa, natureza exploratória e utilizou-se do estudo de caso como método de investigação (HAIR Jr. et al, 2005; CERVO et al, 2007). As duas organizações estudadas têm características semelhantes. Ambas são usina escola de laticínios e, por essa razão, possuem produção reduzida e limitações financeiras. Para a coleta e análise dos dados, foram conduzidas entrevistas semi-estruturadas com os responsáveis pelas empresas e colaboradores, visitas às instalações (observação não-participante) e medições nos locais com maiores perdas, sendo assim utilizadas múltiplas fontes de evidências. Procurou-se visualizar o funcionamento da empresa focando a sequência de atividades que levam os produtos aos clientes (LAURINDO; ROTONDARO, 2006).

A escolha das empresas - bem como o ramo de atuação - foi realizada de forma intencional, devido à importância do segmento (laticínios) e da região para o panorama econômico do Estado do RS, conforme descrito na introdução deste trabalho. A primeira empresa, a Usina Escola de Laticínios da Universidade Federal de Santa Maria (UFSM), foi criada na década de 1970 e tem capacidade para processar 3.960.000 litros/ano de leite. A matéria prima é fornecida por associados da Cooperativa Regional da Reforma Agrária Mãe da Terra (Cooperterra) de Tupanciretã-RS, que são produtores e integrantes de assentamentos da reforma agrária.

O segundo local escolhido é a usina escola de laticínios da Sociedade Educacional Três de Maio (SETREM), situada na cidade de Três de Maio-RS. A usina possui três funcionários e possui capacidade para processar aproximadamente 105.600 litros/ano de leite.

As etapas da pesquisa encontram-se no fluxograma da Figura 2. 
Figura 2 - Fluxograma de metodologia da pesquisa

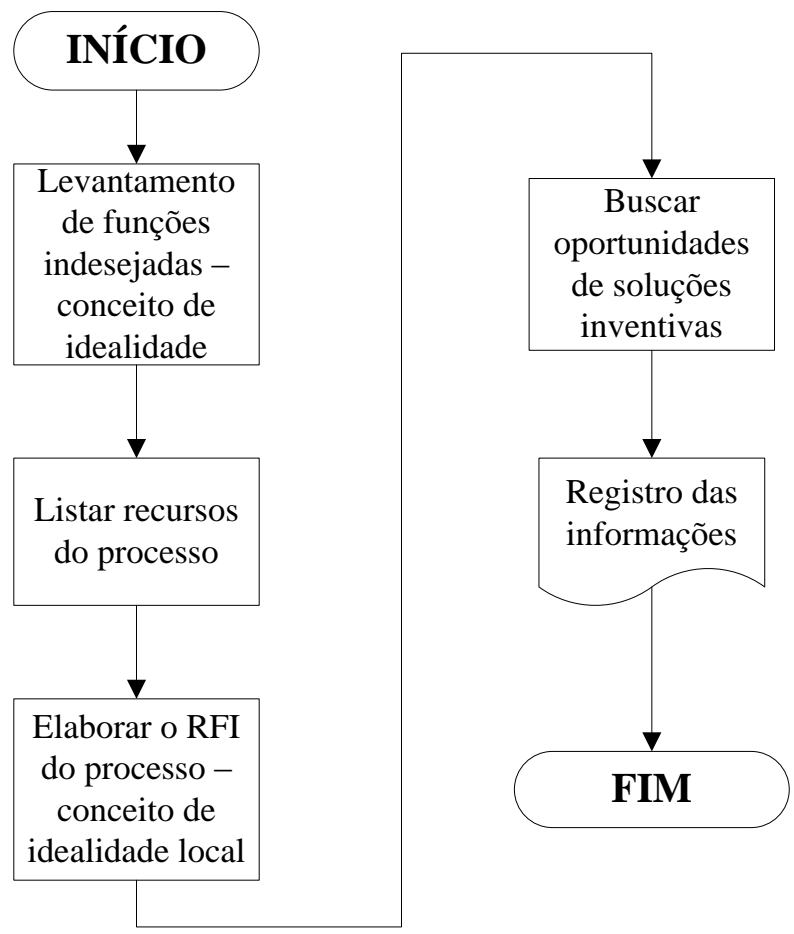

Fonte: Autoria própria (2011)

\section{Resultados e discussões}

O processo de beneficiamento do leite e derivados foi observado e todas as instalações de ambas as usinas foram avaliadas. A partir da metodologia da PML, alinhada aos conceitos fundamentais da TRIZ, foram detectadas oportunidades de melhoria nos processos produtivos das usinas. Entre essas, destacam-se a necessidade de melhor gerenciamento no uso da água e a busca pelo reaproveitamento de subproduto. A seguir, são descritos os resultados das pesquisas nas duas usinas.

\subsection{Funções indesejadas, recursos e Resultado Final Ideal (RFI) dos processos}

Dentro da usina da UFSM, na recepção das matérias-primas, é feita a higienização das embalagens de armazenamento do leite oriundo dos produtores, das caixas plásticas usadas no transporte do leite envasado e outros produtos. Dois tanques de 500 litros são utilizados para imersão do material a ser limpo, ocorrendo um consumo diário de aproximadamente 2.000 litros de água - equivalente a $528 \mathrm{~m}^{3} / \mathrm{ano}$.

Durante a pasteurização do leite, uma quantidade elevada de água é consumida no processo, bem como o vapor originado da caldeira. A água é eliminada por meio de uma tubulação ao lado da bacia de pasteurização. Através de medidas no local, estimou-se um desperdício aproximado de 3.000 litros por hora - equivalente a 4.752 m³/ano de água perdida (Figura 3). 
Figura 3 - Perdas de água na pasteurização do leite cru na usina da UFSM

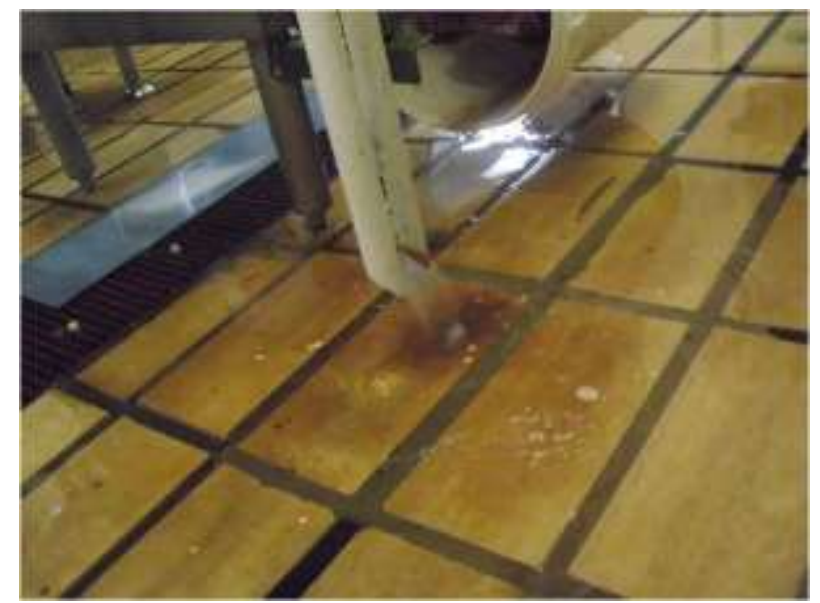

Fonte: Kubota et al (2010)

Também foram detectados desperdícios de vapor em acessórios e conexões que transportam o mesmo para os processos produtivos (Figura 4), resultando em maior consumo de lenha e água na caldeira da empresa. No setor de envase (embalagem) de queijos, constatou-se a ausência de porta com isolamento térmico, bem como uma janela basculante de vidro simples, o que é indesejado devido à passagem de calor do meio externo ao setor (Figura 5).

Figura 4 - Perdas de vapor na pasteurização do leite e próximo a caldeira
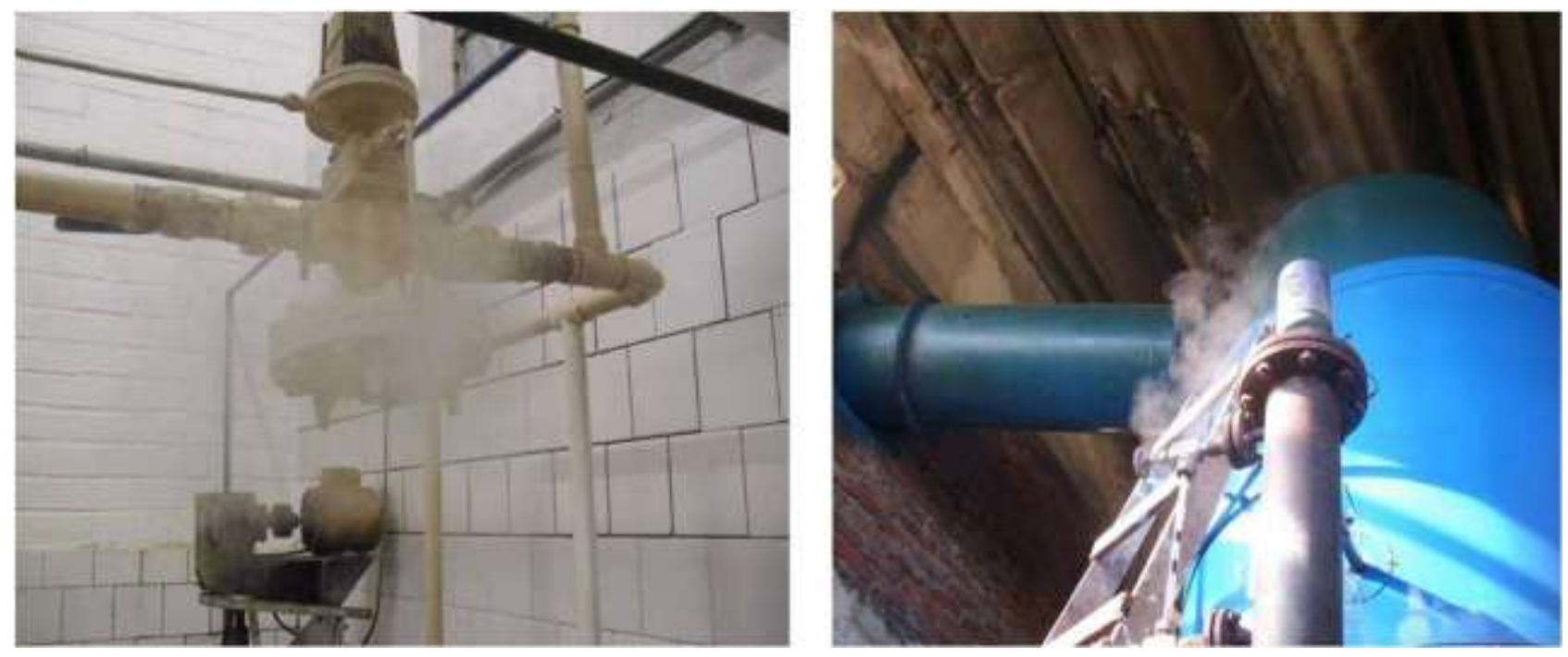

Fonte: Kubota et al (2010) 
Figura 5 - Perdas térmicas no setor de envase de queijos: abertura no acesso (ausência de porta) e janela basculante
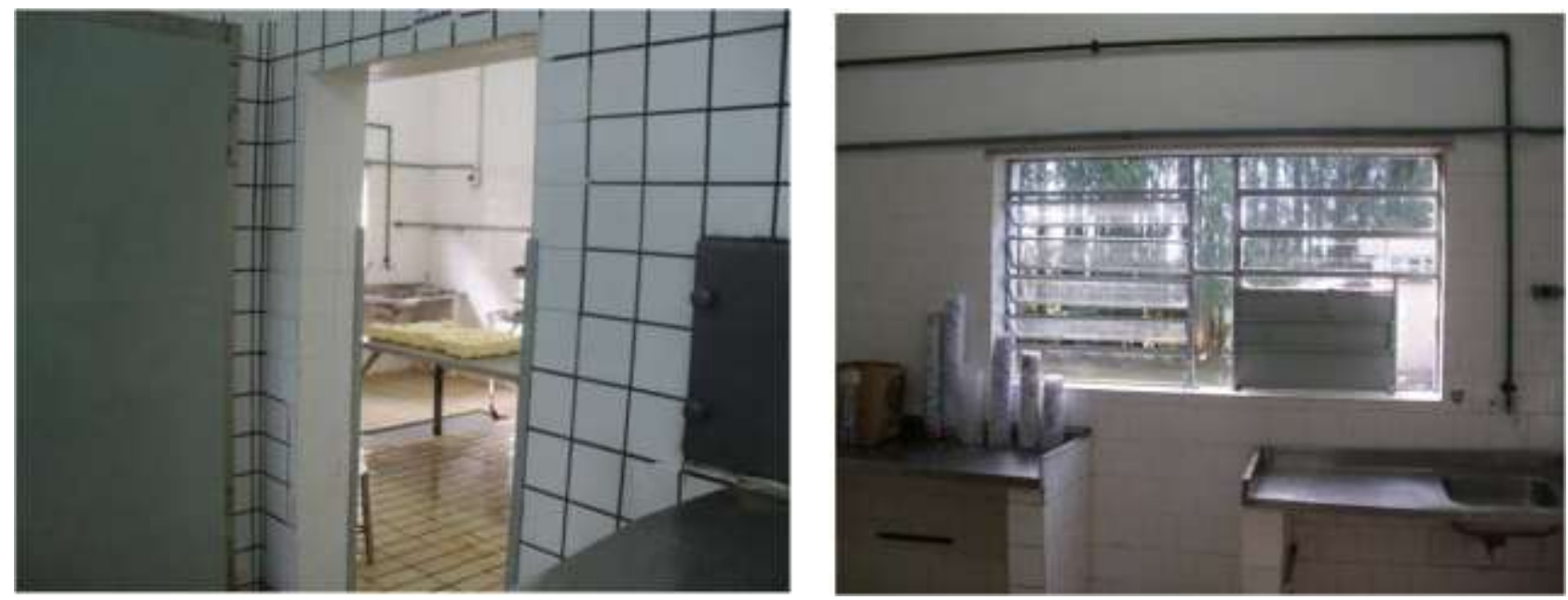

Fonte: Kubota et al (2010)

No caso da usina da SETREM, o processo de higienização dos equipamentos da produção é realizado manualmente, através de mangueiras. Entretanto, por vezes foi observado que a mesma fica em repouso no piso, enquanto a água é desperdiçada. Esse procedimento consome em torno de $132 \mathrm{~m}$ 3/ano, sendo a atividade com maior consumo de água na empresa (Figura 6). Além disso, ocorrem perdas de água nos processos de pasteurização e envase do leite e fabricação do iogurte, as quais foram mensuradas em 149,13 mªno, sendo que o efluente perdido é limpo e com potencial reaproveitamento nos processos produtivos (Figura 6).

Figura 6 - Perdas de água na pasteurização e envase do leite, fabricação de iogurte e higienização
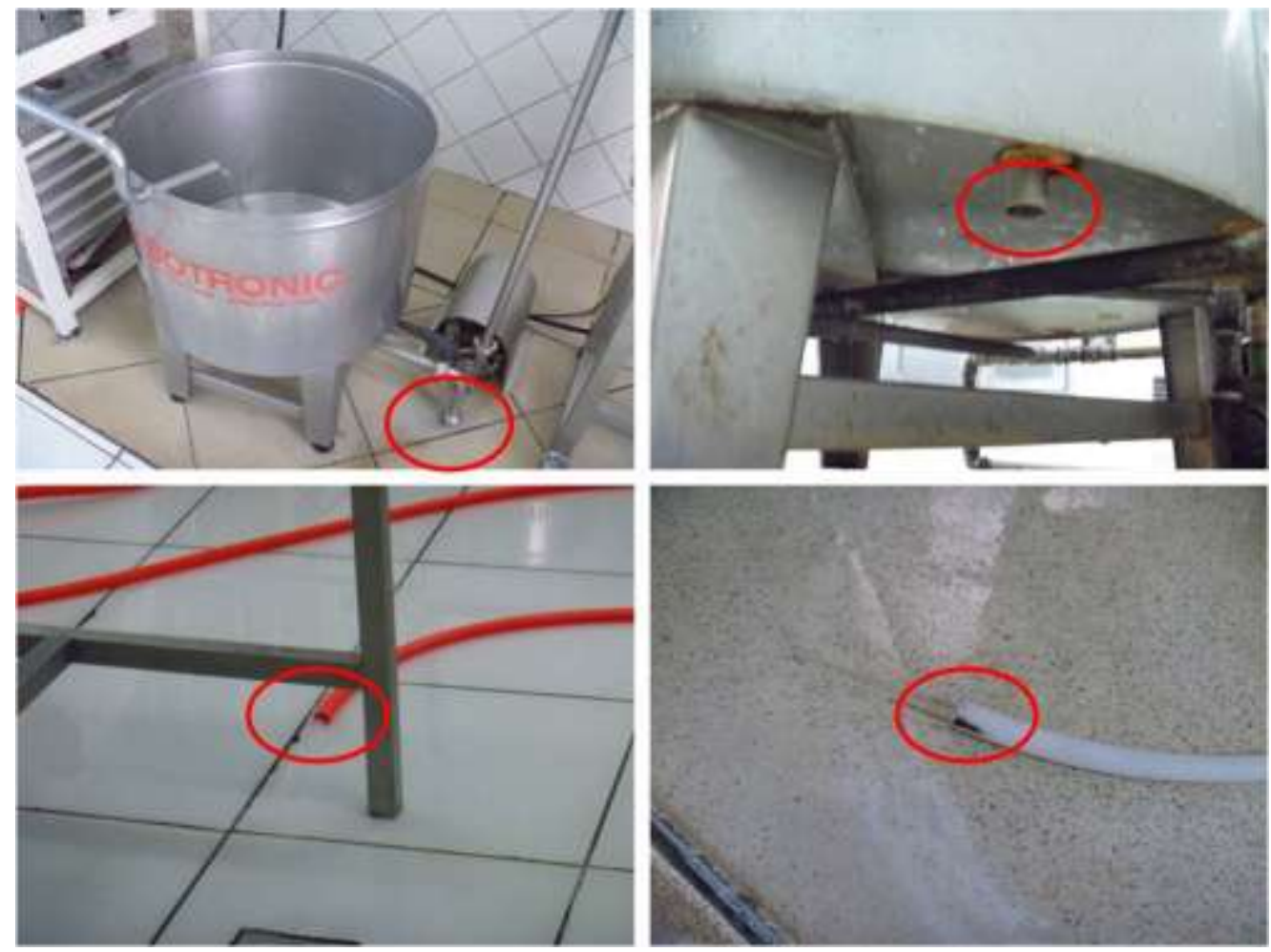

Fonte: Autoria própria (2011) 
Ainda na mesma empresa, o processo de dessoragem, na fabricação do queijo, também representa problema crítico e função indesejada, pois o soro gerado no processo não é aproveitado posteriormente. As perdas com esse subproduto são de 3.168 litros/ano. Após o conhecimento dos processos críticos, foi possível encontrar as funções indesejadas dos mesmos. O Quadro 1 apresenta as funções indesejadas em cada uma das situações.

Quadro 1 - Funções indesejadas dos processos estudados

\begin{tabular}{|c|c|c|}
\hline Unidade de análise & Processo (s) & Função indesejada \\
\hline \multirow{4}{*}{ Usina - UFSM } & Recepção de matérias-primas & $\begin{array}{l}\text { Água excessiva na lavagem de caixas } \\
\qquad\left(528 \mathrm{~m}^{3} / \mathrm{ano}\right)\end{array}$ \\
\hline & Pasteurização do leite cru & $\begin{array}{l}\text { Água perdida no processo (Figura } 3 \text { ) - } \\
4.752 \mathrm{~m}^{3} / \mathrm{ano}\end{array}$ \\
\hline & Pasteurização e caldeira & $\begin{array}{c}\text { Perdas de vapor em acessórios ou } \\
\text { juntas na tubulação distribuidora } \\
\text { (Figura 4) }\end{array}$ \\
\hline & Envase (embalagem) de queijos & $\begin{array}{c}\text { Perdas térmicas - falta de isolamento } \\
\text { no envase de queijos (Figura 5) }\end{array}$ \\
\hline \multirow{3}{*}{ Usina - SETREM } & Higienização das instalações & $\begin{array}{c}\text { Água excessiva na lavagem dos } \\
\text { equipamentos da produção }(132 \\
\text { mªno) - Figura } 6\end{array}$ \\
\hline & Pasteurização, envase e iogurte & $\begin{array}{l}\text { Água perdida nos processos (Figura 6) } \\
-149,13 \mathrm{~m}^{3} / \mathrm{ano}\end{array}$ \\
\hline & Dessoragem & $\begin{array}{c}\text { Soro residual não aproveitado (3.168 } \\
\text { litros/ano) }\end{array}$ \\
\hline
\end{tabular}

Fonte: Autoria própria (2011)

No processo produtivo, constatou-se que a água é um recurso reutilizável. Adicionalmente, o soro gerado na fabricação do queijo também é um recurso não utilizado e reaproveitável, denominado recurso de substância (CARVALHO, 2007). Vapor e energia térmica também são recursos de substância, e suas perdas poderiam ser minimizadas. Assim, por meio das funções indesejadas, elaborou-se a idealidade, onde a situação ideal é a inexistência de: consumo de água; consumo de energia térmica e de vapor, e; geração de soro.

Entretanto, considerando que essas situações ainda são utópicas, uma vez que, nos casos estudados, não se pode - ainda - higienizar as instalações sem uso de água, resfriar e/ou congelar os produtos sem consumo de energia térmica, aquecimento sem utilização de vapor e produção de queijo sem a geração de soro, foram propostas soluções que minimizem o consumo dos recursos citados. Dessa maneira é que se gera o Resultado Final Ideal (RFI) para os problemas detectados, expostos no Quadro 2. 
Quadro 2 - Resultado Final Ideal (RFI) para as funções indesejadas

\begin{tabular}{|c|c|c|}
\hline Unidade de análise & Função indesejada & Resultado Final Ideal (RFI) \\
\hline \multirow{4}{*}{ Usina - UFSM } & $\begin{array}{l}\text { Água excessiva na lavagem de } \\
\text { caixas }\left(528 \mathrm{~m}^{3} / \text { ano }\right)- \\
\text { Recepção de matéria-prima }\end{array}$ & $\begin{array}{l}\text { Redução no consumo de água para } \\
\text { lavagem de caixas e produtos na } \\
\text { recepção }\end{array}$ \\
\hline & $\begin{array}{l}\text { Água perdida no processo } \\
\text { (Figura 3) }-4.752 \mathrm{~m}^{3} / \mathrm{ano}- \\
\text { Pasteurização do leite }\end{array}$ & $\begin{array}{l}\text { Reaproveitamento por completo da } \\
\text { água perdida }\end{array}$ \\
\hline & $\begin{array}{c}\text { Perdas de vapor em acessórios } \\
\text { ou juntas na tubulação } \\
\text { distribuidora (Figura 4) - } \\
\text { Pasteurização do leite e } \\
\text { Caldeira }\end{array}$ & $\begin{array}{c}\text { Minimização das perdas nos locais } \\
\text { observados }\end{array}$ \\
\hline & $\begin{array}{c}\text { Perdas térmicas - falta de } \\
\text { isolamento no envase de } \\
\text { queijos (Figura 5) }\end{array}$ & $\begin{array}{c}\text { Minimização de perdas de calor no } \\
\text { setor }\end{array}$ \\
\hline \multirow{3}{*}{ Usina - SETREM } & $\begin{array}{c}\text { Água excessiva na lavagem } \\
\text { dos equipamentos da produção } \\
\left(132 \mathrm{~m}^{3} / \mathrm{ano}\right) \text { - Figura } 6\end{array}$ & $\begin{array}{l}\text { Redução no consumo de água para } \\
\text { higienização, utilizando-se de alta } \\
\text { pressão }\end{array}$ \\
\hline & $\begin{array}{c}\text { Água perdida nos processos } \\
\text { (Figura 6) - 149,13 mªno }\end{array}$ & $\begin{array}{c}\text { Reaproveitamento da água perdida } \\
\text { nos processos }\end{array}$ \\
\hline & $\begin{array}{c}\text { Soro residual não aproveitado } \\
\text { (3.168 litros/ano) - } \\
\text { Dessoragem (queijo) }\end{array}$ & $\begin{array}{l}\text { Utilização do soro residual como } \\
\text { matéria-prima para outros processos } \\
\text { relativos à indústria de laticínios }\end{array}$ \\
\hline
\end{tabular}

Fonte: Autoria própria (2011)

Desse modo, por meio dos RFI elaborados, pode-se partir para a busca de oportunidades de PML nas situações descritas.

\subsection{Levantamento de oportunidades de PML}

Depois de organizados os RFIs de cada um dos problemas, partiu-se para a elaboração de estratégias de eliminação e/ou minimização dos mesmos. Com isso, realizou-se a última etapa desta pesquisa, a geração de oportunidades PML. Os resultados deste levantamento se encontram no Quadro 3.

Quadro 3 - Propostas de solução inventiva para cada RFI elaborado

\begin{tabular}{|c|c|c|}
\hline Unidade de análise & Resultado Final Ideal (RFI) & Proposta de solução \\
\hline \multirow{7}{*}{ Usina - UFSM } & $\begin{array}{l}\text { Redução no consumo de água } \\
\text { para lavagem de caixas e } \\
\text { produtos na recepção }\end{array}$ & $\begin{array}{l}\text { Aquisição de equipamento para lavagem } \\
\text { automática de caixas. Possibilidade de } \\
\text { redução no consumo de água }\end{array}$ \\
\hline & $\begin{array}{l}\text { Reaproveitamento por } \\
\text { completo da água perdida }\end{array}$ & $\begin{array}{l}\text { Sistema de tubulação com bomba }(2 \mathrm{CV}) \text { e } \\
\text { reservatório de água }(10.000 \text { l) para } \\
\text { reutilização da água no processo }\end{array}$ \\
\hline & $\begin{array}{l}\text { Minimização das perdas de } \\
\text { vapor nos locais observados }\end{array}$ & $\begin{array}{l}\text { Implantação de um programa de } \\
\text { manutenção corretiva, preventiva e preditiva } \\
\text { para manter as conexões e instalações em } \\
\text { bom estado de uso }\end{array}$ \\
\hline & \multirow{4}{*}{$\begin{array}{l}\text { Minimização de perdas de } \\
\text { calor no setor }\end{array}$} & $\begin{array}{c}\text { Instalação de porta “vai-e-vem” em aço e } \\
\text { PVC flexível }\end{array}$ \\
\hline & & Instalação de cortinas de PVC flexível \\
\hline & & $\begin{array}{l}\text { Fechamento da janela basculante existente } \\
\text { com alvenaria }\end{array}$ \\
\hline & & $\begin{array}{l}\text { Substituição da janela basculante por janela } \\
\text { com isolamento térmico }\end{array}$ \\
\hline
\end{tabular}




\begin{tabular}{|c|c|c|}
\hline \multirow{8}{*}{ Usina - SETREM } & $\begin{array}{l}\text { Redução no consumo de água } \\
\text { para higienização, utilizando- } \\
\text { se de alta pressão }\end{array}$ & Aquisição de lavadora de alta pressão \\
\hline & $\begin{array}{l}\text { Reaproveitamento da água } \\
\text { perdida nos processos }\end{array}$ & $\begin{array}{l}\text { Sistema de tubulação com bomba }(2 \mathrm{CV}) \\
\text { para reutilização da água no processo }\end{array}$ \\
\hline & \multirow{6}{*}{$\begin{array}{l}\text { Utilização do soro residual } \\
\text { como matéria-prima para } \\
\text { outros processos relativos à } \\
\text { indústria de laticínios }\end{array}$} & $\begin{array}{l}\text { Alimentação de suínos (BERTOL, GOMES } \\
\text { e SILVA, 1993; ZARDO e LIMA, 1999; } \\
\text { CERDAN e SAUTIER, 2003; LIZIEIRE e } \\
\text { CAMPOS, 2006) }\end{array}$ \\
\hline & & $\begin{array}{l}\text { Fabricação de bebida láctea (MENEZES, } \\
\text { 2011) }\end{array}$ \\
\hline & & $\begin{array}{l}\text { Fabricação de doce de leite (MORAES et al, } \\
\text { 2009) }\end{array}$ \\
\hline & & $\begin{array}{l}\text { Fabricação de pão de forma (CALDAS, } \\
\text { 2008) }\end{array}$ \\
\hline & & $\begin{array}{l}\text { Fabricação de ricota (CHAVES, } \\
\text { CALLEGARO e SILVA, 2010) }\end{array}$ \\
\hline & & $\begin{array}{l}\text { Fabricação de sorvete (SILVA e BOLINI, } \\
\text { 2006) }\end{array}$ \\
\hline
\end{tabular}

Fonte: Autoria própria (2011)

Desse modo, ressaltam-se as diversas oportunidades disponíveis que podem ser analisadas para posterior implantação. Técnica e ambientalmente, as propostas são viáveis, necessitando-se, previamente, de análise econômica para se conhecer qual a proposta mais atrativa para posterior implantação pelas unidades de análise em questão.

\section{Considerações finais}

Este trabalho teve como objetivo a utilização da Teoria da Solução Inventiva de Problemas (TRIZ) na identificação de oportunidades de PML nas empresas estudadas, visando o direcionamento na busca de práticas sustentáveis. Por intermédio da pesquisa, foi possível observar a importância de conceitos da TRIZ na resolução de problemas relacionados à PML, principalmente no que se refere à procura de oportunidades de melhoria a serem estudadas.

Os conceitos de idealidade e recursos mostraram-se relevantes na geração de alternativas para os problemas (funções indesejadas) encontrados. O conceito de função indesejada mostrou-se importante para orientar as equipes envolvidas quanto às situações prejudiciais ocorrentes na produção. Com isso, foram priorizados os problemas relacionados ao processo de beneficiamento do leite e derivados em ambas as empresas. Em seguida, possibilitou-se aplicar o conceito de recursos, relevante para conhecer o ambiente e os recursos ainda não utilizados nas unidades de análise pesquisadas.

Com base nos conceitos aplicados, foi possível elaborar o Resultado Final Ideal (RFI) em cada uma das situações abordadas neste trabalho, sendo uma etapa significativa para a elaboração das oportunidades de solução inventiva para os problemas encontrados. Percebeu-se, 
adicionalmente, que foi encontrada maior quantidade de oportunidades relacionadas ao reaproveitamento do soro gerado na fabricação do queijo. Nesse contexto foi possível, também, aplicar o princípio da TRIZ o qual afirma que todos os problemas já foram resolvidos, de alguma forma, no passado. Com base na literatura disponível sobre o tema, encontraram-se diversas aplicações do referido subproduto, possibilitando a usina SETREM estudar qual a alternativa mais tangível às suas condições técnicas e financeiras.

Além disso, a TRIZ auxilia, essencialmente, na sistematização do processo de criatividade e procura por soluções inventivas, organizando os problemas e orientando a busca por ideias já utilizadas no passado e presente, visando melhorias futuras nos sistemas estudados.

Como limitação deste estudo, ressalta-se a não realização de estudos aprofundados de viabilidade econômica das oportunidades encontradas. Considerando-se que o foco desta pesquisa é a identificação de melhorias na produção de lácteos, sugere-se, em estudos futuros, que as oportunidades encontradas sejam estudadas na perspectiva financeira, para as unidades de análise escolhidas nos referidos trabalhos, para que tenham condições de avaliar qual das alternativas é a mais atrativa economicamente. Além disso, tratam-se de usinas escolas, que possuem limitações financeiras e porte reduzido. Entretanto, o estudo contribui para melhoria do padrão de gestão ambiental no ramo pesquisado, pois as propostas descritas podem ser replicadas em âmbito regional e nacional, considerando a viabilidade técnica e ambiental das mesmas.

Por fim, espera-se que este trabalho possa servir como um guia para a compreensão e aplicação dos conceitos fundamentais e ferramentas básicas da TRIZ em processos produtivos, facilitando o entendimento da metodologia e proporcionando oportunidade de estudos acerca do tema. Assim, conclui-se que os conceitos da metodologia TRIZ podem oferecer suporte à produção mais limpa (PML), explicitando as funções indesejadas - do ponto de vista ambiental - dos processos, organizando os recursos não aproveitados no sistema e orientando para a idealidade nas situações problemáticas pesquisadas, auxiliando na geração de soluções e posterior tomada de decisão.

\section{Abstract}

Innovation and improved results in production have been essential requirements in the food industry. In parallel, simple and creative ideas contribute for improving enterprises. Thereby, this paper aims to investigate cleaner production (CP) opportunities through the Theory if Inventive Problem Solving (TRIZ), searching for critical points in small dairy industries production. To perform the survey, it was carried out a qualitative and exploratory research, with a case study in two small dairy plants in Rio Grande do Sul (RS). The results show several CP opportunities in the studied cases, mainly in wastewater and whey loss in the production processes. Thus, it was concluded that the TRIZ's concepts were important in organizing the creative process, clarifying the definition of the problems encountered and, ultimately, in the pursuit for inventive solutions.

Key-words: cleaner production, TRIZ, dairy industry, process improvement. 


\section{Referências}

BARROS, A. I. S.; LEHFELD, N. A. S. Fundamentos de Metodologia Científica. 3. ed. São Paulo: Pearson Makron Books, 2007.

BERLIN, J.; SONESSON, U.; TILLMAN, A. M. A life cycle based method to minimise environmental impact of dairy production through product sequencing. Journal of Cleaner Production, v. 15, n. 4, p. 347-356, 2007.

cross ref

BERTOL, T. M.; GOMES, J. D. F.; SILVA, E. D. Soro de leite integral na alimentação de suínos em crescimento e terminação. Revista da Sociedade Brasileira de Zootecnia, v. 22, n. 6, p. 993-1002, 1993.

BRUM, L. F. W.; SANTOS JÚNIOR, L. C. O.; BENEDETTI, S. Reaproveitamento de Água de Processo e Resíduos da Indústria de Laticínios. In: INTERNACIONAL WORKSHOP ADVANCES IN CLEANER PRODUCTION, 2, 2009, São Paulo. Anais... Disponível em:

<http://www.advancesincleanerproduction.net/second/files/sessoes/4a/5/L.\%20F.\%20W.\%20Brum\%20\%20Resumo\%20Exp.pdf>. Acesso em: 19 mai. 2011.

CALDAS, M. C. S. Aproveitamento de soro de leite na elaboração de pão de forma. 2008. 67f. Dissertação (Mestrado em Ciência e Tecnologia de Alimentos) - Universidade Federal da Paraíba, João Pessoa, 2008.

CARVALHO, M. A. Metodologia IDEATRIZ para a Ideação de Novos Produtos. 2007. 254f. Tese (Doutorado em Engenharia de Produção) - Universidade Federal de Santa Catarina, Florianópolis, 2007.

CARVALHO, M. A.; BACK, N. Uso dos conceitos fundamentais da TRIZ e do método dos princípios inventivos no desenvolvimento de produtos. In: CONGRESSO BRASILEIRO DE GESTÃO DE DESENVOLVIMENTO DE PRODUTO, 2, 2001, Florianópolis. Anais... Disponível em: 〈http://www.decarvalho.eng.br/macartigoiiicbgdp.pdf>. Acesso em: 10 jun., 2011.

CARVAlhO, M. A.; FERREIRA, C. V. A TRIZ e sua Utilização no Processo de Desenvolvimento de Produto. In: OLIVEIRA, J. F. G.; GUERRINI, F. M.; AMARAL, D. C. (Org.) Gestão do Ciclo de Vida dos Produtos. Jaboticabal: Novos Talentos, 2005, cap. 13, p. 181-194.

CARVALHO, M. A.; HATAKEYAMA, K. Solução inventiva de problemas e engenharia automotiva - a abordagem da TRIZ. 2003. Disponível em: <http://www.aditivaconsultoria.com/artigoengautomotivaeaerospacialmarcoekazuo.pdf>. Acesso em: 10 jul. 2011.

CERDAN, C. T.; SAUTIER, D. Sistemas de intermediação e valorização econômica dos produtos. In: SABOURIN, E.; CARON, P. Camponeses do sertão. Mutação das agriculturas no Nordeste do Brasil. Brasília: Embrapa Informação Tecnológica, p. 179-200, 2003.

CERVO, A. L.; BERVIAN, P. A.; SILVA, R. Metodologia Científica. 6. ed. São Paulo: Pearson Prentice Hall, 2007.

CHAVES, K. F.; CALLEGARO, E. D.; SILVA, V. R. O. Utilização do soro de leite nas indústrias de laticínios da região de Rio Pomba-MG. In: CONGRESSO NACIONAL DE LATICÍNIOS, 27, 2010, Juiz de Fora-MG. Anais... Disponível em: 〈http://www.cnlepamig.com.br/anais/img/trabalhos_cnl/poster/043.pdf〉. Acesso em: 15 ago., 2011.

CHEN, J. L.; LIU, C. An eco-innovative design approach incorporating the TRIZ method without contradiction analysis. The Journal of Sustainable Product Design, v. 1, n. 4, p. 263-272, 2001.

cross ref

COUTINHO, J. P.; RODRIGUES, L. B.; SILVA, C. A. Implantação de uma estratégia para reaproveitamento do óleo de fritura residual em um restaurante industrial. In: SIMPÓSIO DE ENGENHARIA DE PRODUÇÃO, 16, 2009, Bauru. Anais... Disponível em: <http://www.simpep.feb.unesp.br/anais_simpep.php?e=4>. Acesso em: 24 jun. 2011.

DEMARQUE, E. TRIZ - teoria para a resolução de problemas inventivos aplicada ao planejamento de processos na indústria automotiva. Trabalho de conclusão de curso do mestrado profissionalizante. Engenharia Automotiva. Escola Politécnica da Universidade de São Paulo, 2005.

EMPRESA BRASILEIRA DE PESQUISA EM AGROPECUÁRIA (EMBRAPA). Ranking da Produção Anual de Leite por Estado no Brasil - 2007. Disponível em: <http://www.cnpgl.embrapa.br/>. Acesso em: 27 jul. 2011. 
FISHER, P. M. J.; SCOTT, R. Evaluating and controlling pharmaceutical emissions from dairy farms: a critical first step in developing a preventative management approach. Journal of Cleaner Production, v. 16, n. 14, p. 1437-1446, 2008.

\section{cross ${ }^{\text {ref }}$}

FOOD AND AGRICULTURE ORGANIZATION OF THE UNITED NATIONS (FAO). Produção mundial de leite 2008. Disponível em: <http://faostat.fao.org/site/569/DesktopDefault.aspx?PageID=569\#ancor>. Acesso em: 27 jul. 2011.

FREITAS, P.; RIBAS, L. Gestão ambiental em uma empresa de laticínios de Toledo, Paraná: um estudo de caso. In: SIMPÓSIO DE ENGENHARIA DE PRODUÇÃO, 15, 2008, Bauru. Anais... Bauru: Unesp, 2008. Disponível em: <http://www.simpep.feb.unesp.br/anais_simpep.php?e=2>. Acesso em: 24 jun. 2011.

FRESNER, J.; JANTSCHGI, J.; BIRKEL, S.; BÄRNTHALER, J.; KRENN, C. The theory of inventive problem solving (TRIZ) as option generation tool within cleaner production projects. Journal of Cleaner Production, v. 18, n. 2, p. 128-136, 2010.

cross' ref

HAIR Jr., J. F. P. J.; BABIN, B.; MONEY, A. H.; SOMOUEL, P. Fundamentos de métodos de pesquisa em administração. São Paulo: Bookman, 2005.

HOCKERTS, K. Eco-efficient service innovation: increasing business - ecological efficiency of products and services, in charter. In: Greener M, editor. Marketing: a global perspective on greener marketing practice. Sheffield, UK: Greenleaf Publishing, p. 95-108, 1999.

JANTSCHGI, J.; MANN, D. Fostering methodical Product - and Process - Development by Combining TRIZ-Tools and Sustainable Development. TRIZ Journal, v. 2, n. 4, 2005. Disponível em: <http://www.trizjournal.com/archives/2005/02/04.pdf>. Acesso em: 23 jun. 2011.

JONES, E.; MANN, D. An eco-innovation case study of domestic dishwashing through the application of TRIZ tools. Creativity and Innovation Management, v. 10, n. 1, p. 3-14, 2001.

cross ref

KOBAYASHI, H. A systematic approach to eco-innovative product design based on life cycle planning. Advanced Engineering Informatics, v. 20, n. 2, p. 113-125, 2006.

cross ref

KUBOTA, F. I.; SILVA FILHO, D. P.; ROSA, L. C. Produção mais limpa: introdução de práticas no melhoramento de processos em usina escola de laticínios. In: SIMPÓSIO DE ENGENHARIA DE PRODUÇÃO, 17, 2010, Bauru. Anais... Bauru: Unesp, 2010. Disponível em: 〈http://www.simpep.feb.unesp.br/anais_simpep.php?e=5>. Acesso em: 22 jun. 2011.

LAURINDO, F. J. B.; ROTONDARO, R. G. Gestão integrada de processos e da tecnologia da informação. São Paulo: Atlas, 2006.

LI, X. N.; RONG, B. G.; KRASLAWSKI, A. TRIZ-Based Creative Retrofitting of Complex Distillation Processes - An Industrial Case Study. European Symposium on Computer Aided Process Engineering, v. 11, p. 439-444, 2001.

LIZIEIRE, R. S.; CAMPOS, O. F. Soro de queijo "in natura" na alimentação do gado de leite. Instrução técnica para o produtor de leite. $2^{a}$ Edição. Juiz de Fora: Embrapa Gado de Leite, 2006. Disponível em:

<http://www.cileite.com.br/sites/default/files/44Instrucao.pdf>. Acesso em: 27 jul. 2011.

MALKIN, S.; MALKIN, A. Eureka on Demand. Ideation International Inc. 2003. Disponível em: <http://www.ideationtriz.com>. Acesso em: 20 ago. 2011.

MEDEIROS, D. D.; CALÁBRIA, F. A.; SILVA, G. C. S.; SILVA FILHO, J. C. V. Aplicação da Produção mais Limpa em uma empresa como ferramenta de melhoria contínua. Revista Produção, v. 17, n. 1, p. 109-128, 2007.

cross ref 
MENDES, L. Gestão ambiental, custo ou benefício para a micro e pequena empresa: um estudo de caso no setor de laticínios. VI SEMEAD - Seminários em Administração, 6., 2004, São Paulo. Anais... São Paulo: USP, 2003.

Disponível em: <http://www.ead.fea.usp.br/Semead/6semead/index.htm>. Acesso em: 15 jun. 2011.

MENEZES, A. C. S. Desenvolvimento de bebida láctea fermentada à base de soro de leite e polpa de cajá (Spondias mombin l.) com potencial atividade probiótica. 2011. 106f. Dissertação (Mestrado em Ciência e Tecnologia de Alimentos) - Universidade Federal Rural de Pernambuco, Recife, 2011.

MORAES, A. H.; RUSTICK, A.; ROBERTI, E.; BRATZ, R.; STEIN, M. Desenvolvimento de projeto para um novo produto: doce de leite com soro de leite e amendoim torrado. In: SALÃO DE PESQUISA SETREM, 7, Três de Maio. Anais... Disponível em: <http://sites.setrem.com.br/saps/2009/index.html>. Acesso em: 16 ago., 2011.

NGUYEN, M. H.; DURHAM, R. J. Status and prospects for cleaner production in the dairy food industry. Australian Journal of Dairy Technology, v. 59, n. 2, p. 171-173, 2004.

ÖZBAY, A.; DEMIRER, G. N. Cleaner production opportunity assessment for a milk processing facility. Journal of Environmental Management, v. 84, n. 4, p. 484-493, 2007.

cross ref

RIGHETTI, C. C.; RODRIGUES, I.; FACÓ, J. F. B.; SAKURAMOTO, J. C. B. Estratégias de Gestão Ambiental nas Empresas: um Estudo de Caso sobre o Papel Reciclado. In: ENCONTRO ANUAL DA ASSOCIAÇÃO NACIONAL DOS PROGRAMAS DE PÓS-GRADUAÇÃO EM ADMINISTRAÇÃO, 29, Brasília. Anais... Brasília: Unb, 2005. Disponível em:

<http://www.anpad.org.br/evento.php?acao=trabalho\&cod_edicao_subsecao=30\&cod_evento_edicao=9\&cod_edicao_t rabalho=160>. Acesso em: 28 jun. 2011.

SILVA, D. J. P. Diagnóstico do consumo de água e da geração de efluentes em uma indústria de laticínios e desenvolvimento de um sistema multimídia de apoio. $88 \mathrm{f}$. Dissertação (Mestrado em Ciência e Tecnologia de Alimentos) - Universidade Federal de Viçosa, Viçosa, 2006.

SILVA, K.; BOLINI, H. M. A. Avaliação sensorial de sorvete formulado com produto de soro ácido de leite bovino. Ciência e Tecnologia dos Alimentos, Campinas, v. 26, n. 1, p. 116-122, 2006.

SILVA, M. A.; QUEIROZ, R. F. M.; CELESTINO, J. E. M.; MATTOS, K. M. C. Gerenciamento dos resíduos como ferramenta para uma produção mais limpa no ramo de panificação. In: SIMPÓSIO DE ENGENHARIA DE PRODUÇÃ̃, 16, Bauru. Anai... Bauru: Unesp, 2009. Disponível em:

<http://www.simpep.feb.unesp.br/anais_simpep.php?e=4>. Acesso em: 20 jun. 2011.

THRANE, M.; NIELSEN, E. H.; CHRISTENSEN, P. Cleaner production in Danish fish processing - experiences, status and possible future strategies. Journal of Cleaner Production, v. 17, n. 3, p. 380-390, 2009.

cross ref

UNITED NATIONS ENVIRONMENTAL PROGRAMME - UNEP. Changing production patterns: Learning from the experience of national cleaner production centers. Paris: United Nations Publication, 2002.

YANG, C. J.; CHEN, J. L. Accelerating preliminary eco-innovation design for products that integrates case-based reasoning and TRIZ method. Journal of Cleaner Production, v. 19, n. 9-10, p. 998-1006, 2011.

cross ${ }^{\text {ref }}$

ZARDO, A. O.; LIMA, G. J. M. M. Alimentos para suínos. Boletim Informativo da Empresa Brasileira de Pesquisa Agropecuária - EMBRAPA - e Emater/RS, 1999. Disponível em:

<http://www.suinoculturaindustrial.com.br/PortalGessulli/AppFile/Material/Tecnico/alimentosuino.pdf>. Acesso em: 19 jul. 2011.

\section{Dados dos autores:}

\section{Nome completo: Flávio Issao Kubota}

Filiação institucional: Universidade Federal de Santa Maria (UFSM) 
Departamento: Departamento de Engenharia de Produção e Sistemas (DEPS)

Função ou cargo ocupado: Mestrando - bolsista CAPES

Endereço completo para correspondência (bairro, cidade, estado, país e CEP): Departamento de Engenharia de Produção e Sistemas, Centro de Tecnologia, UFSM, Campus Camobi, Bairro

Camobi, Santa Maria, Rio Grande do Sul, Brasil, CEP 97105-900

Telefones para contato: (55) 3220-8442

e-mail: flavioissao.kubota@gmail.com

\section{Nome completo: Leandro Cantorski da Rosa}

Filiação institucional: Universidade Federal de Santa Maria (UFSM)

Departamento: Departamento de Engenharia de Produção e Sistemas (DEPS)

Função ou cargo ocupado: Professor do Programa de Pós-Graduação em Engenharia de Produção

Endereço completo para correspondência (bairro, cidade, estado, país e CEP): Departamento de

Engenharia de Produção e Sistemas, Centro de Tecnologia, UFSM, campus Camobi, Bairro

Camobi, Santa Maria, Rio Grande do Sul, Brasil, CEP 97105-900

Telefones para contato: (55) 3220-8442

e-mail: leski78@hotmail.com

Recebido em: 25/08/2011

Aceito em: 05/10/2012 